\title{
IMPACTOS DA IMPLEMENTAÇÃO DA NORMA NBR ISO 14001 EM UMA ORGANIZAÇÃO SUCROALCOOLEIRA
}

\begin{abstract}
NEGREIROS, Cinthia ${ }^{1}$
AMBROZINI, Marcelo Augusto ${ }^{2}$
\end{abstract}

Recebido em: 2009-06-20

Aprovado em: 2009-09-28

ISSUE DOI: $10.3738 / 1982.2278 .279$

RESUMO: Na busca da implantação da norma NBR ISO 14001, gera vários impactos nas organizações com a necessidade da realização e implantação do certificado na organização. Essa pesquisa foi realizada em uma empresa brasileira do setor sucroalcooleiro , com o propósito de apresentar as ações que serão implantadas, na busca de identificar, avaliar e preservar os impactos causados ao meio ambiente, por suas atividades desenvolvidas e meios de produção. A organização escolhida para pesquisa é a Usina Alta Mogiana fundada em 1983, no município de São Joaquim da Barra, estado de São Paulo, atuando no mercado há mais de vinte anos, no comércio de açúcar e álcool, buscando a satisfação de seus clientes internos e externos, por acreditar ser esta a razão da existência do seu empreendimento e assegurar a qualidade, segurança alimentar dos seus produtos, segurança e a saúde ocupacional dos seus colaboradores e o respeito total ao meio ambiente. Através dos dados obtidos conclui - se, que é fundamental as medidas e ações que serão implantadas na organização, nos níveis administrativo, industrial e agrícola na busca do comprometimento e conscientização de todos, na preocupação ambiental. O presente artigo demonstra o desenvolvimento do Sistema Gestão Ambiental, por meio de levantamento e organização de informação, que possibilite maior conscientização da sociedade brasileira sobre a questão da importância gestão ambiental para o desenvolvimento sustentado.

Palavras-chave: Impacto nas organizações. Meio ambiente. Norma NBR ISO 14001.

SUMMARY: On the search for the establish of the NBR ISO 14001 norm, creates lots of impacts on the organizations with the need of certificate's accomplishment and establishment in the organization. This research was made in a Brazilian company of the sugar-ethanol sector, with the purpose to show the actions that will be established on the search of identify, evaluate and protect the impacts caused on the environment, by its developed activities and ways of production. The chosen organization for this research is the Alta Mogiana Mill builds in 1983, on the city council of São Joaquim da Barra, São Paulo State, acting on the market for more than twenty years, on the sugar and ethanol business, looking for his internal and external customers' satisfaction, because they believe that this is the reason of his development's existence and to assure the quality, alimentary security of his products, security and the occupational health of his collaborators and the completely respect to the environment. Through the gained data I conclude that the measures and actions that will be established on the organization are primordial, on the administrative, industrial and agricultural level seeking for the commitment and awareness of everyone on the environment care. The present article shows the environmental management system development, by the survey and information's organization, that can make a bigger awareness on the Brazilian society about the environmental management's importance for the sustainable development.

Keywords: Organizaiton's impact. Environmnet. NBR ISO 14001 norm.

${ }^{1}$ Bacharel em Administração de empresas.
${ }^{2}$ Mestre em Controladoria e Contabilidade. Prof. FFCL/FE. E-mail: marceloambrozini@ yahoo.com.br

Nucleus, v.6, n.2, out.2009 


\section{INTRODUÇÃO}

$\mathrm{O}$ ambiente em que as organizações atuam tem presenciado o surgimento de novos papéis, com alterações nos valores e ideologias em função da preocupação da questão ambiental, procuraram desenvolver atividades no sentido de atender as necessidades ambientais.

As organizações estão cada vez mais preocupadas com o atingimento e demonstração de um desempenho ambiental, coerente com sua política e seus objetivos ambientais,agem assim dentro de um contexto de legislação cada vez mais exigente, do desenvolvimento das políticas econômicas e outras medidas visando adotar a proteção ao meio ambiente e ao desenvolvimento sustentável.

Muitas organizações têm efetuado análises ou auditorias ambientais para avaliar seu desempenho ambiental. Por si só, entretanto tais análise ou auditorias podem não ser suficiente para proporcionar a uma organização a garantia de que seu desempenho atenda os requisitos legais e aos de sua política.

Vem surgindo diversas reivindicações exigidas pela sociedade que afeta o mundo dos negócios, de forma que exige por parte das organizações um posicionamento mais adequado e responsável no sentido de minimizar o risco de degradações ao meio ambiente.

O princípio básico passa a ser a prevenção da poluição envolvendo a seleção das matéria - primas, o desenvolvimento de novos processos e produtos, e o reaproveitamento da energia, a reciclagem de resíduos e a integração com o meio ambiente.

A proteção ambiental deixou de ser função exclusiva de produção para tornar - se também função da área administrativa, na estrutura organizacional, interferindo no planejamento estratégico, função que compõe a organização toda, seja no sentido de desenvolvimento das atividades, seja na discussão de novos cenários alternativos, ou na análise de evolução política, econômica, social, entre normas, metas, e planos de ações.

As normas de gestão ambiental têm por objetivo prover as organizações de elemento de um Sistema da Gestão Ambiental (SGA) eficaz que possa ser integrado a outros requisitos da gestão, e auxiliá - las a alcançar seus objetivos ambientais e econômicos. Não se pretende a estas normas, tais como outras normas, sejam utilizadas para criar barreiras comerciais não tarifárias, nem para ampliar ou alterar as obrigações legais de uma organização.

A norma NBR 14001, são requisitos para que o sistema de gestão ambiental capacite uma organização a desenvolver e implementar política e objetivos que levem em consideração requisitos legais e informações sobre os aspectos ambientais significativos, pretende-se que se 
aplique a todos os tipos e portes de organização e para adequar-se diferentes condições geográficas, culturais e sociais.

O sucesso de um sistema depende do comprometimento de todos os níveis e funções e especialmente da alta administração, um sistema deste tipo permite a uma organização desenvolver uma política ambiental, estabelecer objetivos e um processo para atingir o comprometimento da política em agir conforme necessário, para melhorar seu desempenho e demonstrar a conformidade do sistema com os requisitos dessa norma.

A finalidade geral é equilibrar a proteção ambiental e a prevenção de poluição com as necessidades socioeconômicas Deve-se notar que muitos desses requisitos podem ser abordados simultaneamente ou reapreciados a qualquer momento.

Com isso surge a implantação da norma NBR ISO 14001 com foco principal na proteção ao meio ambiente e a prevenção da poluição equilibrada, com as necessidades sócio-econômicas do mundo atual, com propósito de prover as organizações um sistema de gerenciamento efetivo e ajudá-las a complementar suas políticas para alcançar os objetivos ambientais e econômicos.

A norma NBR ISO 14001 é hoje aceita mundialmente para certificação do Sistema Gestão Ambiental, muito embora sua simples adoção não implique que os problemas de natureza ambiental de uma empresa estejam resolvidos, a ISO 14000, estabelece as diretrizes básicas para a implementação de um sistema de gestão ambiental, o qual constitui um processo estruturado, genérico e completo, com o objetivo de melhoria contínua do desempenho em relação organização, meio ambiente e desenvolvimento sustentável.

Os Sistemas de Gestão Ambiental é uma exigência decorrente da implantação da série ISO 14000, que é uma norma internacional que orienta a qualidade ambiental dentro das organizações, levando em consideração os impactos ambientais dos produtos e processos, desde a fonte de matéria prima até a deposição final do produto sob forma de dejeto, bem como as destinações finais de resíduos durante a produção.

Para uma adequada implantação de Sistemas de Gestão Ambiental, deve contar com o trabalho de pessoas habilitadas e capazes de compreender as implicações deste compromisso assumido pela organização. Tal compromisso deve ser assumido pela direção da organização, que precisa estar perfeitamente consciente da importância da adoção de normas ambientais, passando pela gerência, pois liderarão a mudança até os níveis operacionais que a executarão.

Como uma forma de verificar e divulgar as empresas que apresentam uma postura ambientalmente correta estabeleceu-se sistemas de avaliação de desempenho ambiental, com normas e critérios padronizados em todo o mundo. O conjunto de normas mais aceito na 
gestão ambiental é o da série ISO 14000, cujo objetivo geral é fornecer assistência para as organizações na implantação ou no aprimoramento de um Sistema de Gestão Ambiental (SGA) consistente com a meta do desenvolvimento sustentável e compatível com diferentes estruturas culturais, sociais e organizacionais.

As empresas brasileiras, na busca por manterem-se competitivas, tanto no mercado nacional quanto internacional, estão implantando a gestão ambiental dentro das organizações, pois a sociedade e o Governo estão adquirindo consciência sobre os danos ambientais a sua volta, e se manifestando contra abusos em relação ao meio ambiente. A norma exige das organizações que identifiquem todos os impactos ambientais ou aspectos relacionados, para então implementar ações que melhorem os processos em áreas prioritárias que apresentem aspectos significativos. A ISO 14001 estabelece o melhor procedimento para uma gestão próativa do impacto ambiental de sua organização. Quando possui um Sistema de Gestão Ambiental certificado ISO 14001, vai além do mero cumprimento da lei. O foco passa a ser o aperfeiçoamento constante.

Impactos ambientais gerados pelo desenvolvimento industrial e econômico do mundo atual constituem um grande problema para autoridades e organizações ambientais. No início da década de 90, a ISO viu a necessidade de se desenvolverem normas que tratassem da questão ambiental e tivessem como intuito a padronização dos processos de empresas que utilizassem recursos tirados da natureza e/ou causassem algum dano ambiental decorrente de suas atividades.

A implementação de um Sistema Gestão Ambiental dentro das empresas representa a adoção de um instrumento capaz de gerar um diferencial de qualidade nos mercados internos e externos, nos moldes da melhoria na qualidade e desempenho das suas atividades. No que se refere a certificação ambiental, o número de empresas com certificação ISO 14000 no Brasil cresceu de duas, em 1995, para trezentas e trinta em 2000 (IBAMA).

Esse número pode ser considerado ainda baixo, se comparado com o número total de empresas, potencialmente poluidoras ou não, existentes no país. (IBAMA).

Busca - se comprovar que o desenvolvimento sustentável é o melhor método de inserção para as organizações no atual mercado empresarial. Para certificação da norma NBR ISO 14001, todas as medidas e ações da organização deverão ser avaliadas pela análise dos impactos de suas atividades desenvolvidas e meios de produção no meio ambiente, pelo comprometimento e conscientização de todos os colaboradores da organização pelas práticas e ações de gestão ambiental que resultem em benefícios para o meio ambiente e sociedade como um todo. 
Assim, o caminho a ser percorrido por uma organização que pretenda obter a certificação deve englobar alguns princípios a serem seguidos, como elaboração de uma política ambiental, planejamento, implementação, operação,verificação e análise organizacional para identificar as oportunidades de melhorias que reduzam os impactos das atividades de sua organização sobre o meio ambiente, de forma integrada á situação de conquista mercado e lucratividade.

\section{Quais são as mudanças que a empresa deve fazer para se adequar à implantação da norma NBR ISO 14001 ?.}

O problema apresentado pela pesquisa está relacionado aos impactos causados ao meio ambiente, por uma organização sucroalcooleira, na busca da implantação da norma NBR ISSO 14001. A pesquisa vem com o objetivo de levantar as medidas e ações que serão implantadas pela organização, para identificar e avaliar os benefícios e malefícios causados ao meio ambiente decorrentes de suas atividades desenvolvidas e meio de produção.

A adoção e implantação desta norma, contribuirá, a longo prazo, para a obtenção de resultados ótimos para todas as partes interessadas. Contudo, a adoção dessa norma, por si só não garantirá resultados ambientais ótimos e satisfatórios.

Para atingir os objetivos ambientais, políticos e econômicos pretende-se que o Sistema da Gestão Ambiental estimule a organização a considerar, a implantação das melhores técnicas disponíveis, onde apropriado e economicamente viável, a relação custo-benefício de tais técnicas seja elevada integralmente em consideração, altos benefícios e menores impactos.

O objetivo deste trabalho é fazer um levantamento das mudanças que a empresa deve fazer para se adequar à implementação da NBR ISO 14001.

O objetivo da NBR ISO 14001 é verificar o desenvolvimento sustentável, protegendo o meio ambiente através da prevenção da poluição, administrando os impactos e benefícios ambientais e organizacionais de forma a torna - los compatíveis com a preservação das condições necessárias á vida.

Promover a melhoria contínua em meio ambiente através de Sistema de Gestão, estruturando, avaliando e identificando as atividades e meio de produção, buscando os impactos e benefícios que serão alcançados.

Como redução de custos, devido a eliminação ou minimização de desperdícios, aumento de receitas em conseqüência da melhoria da imagem da empresa no mercado e melhor aceitação de seus produtos e serviços, por credibilidade de seus certificados e responsabilidade organizacional. 


\section{DEFINIÇÃO DA AMOSTRA}

A organização escolhida para pesquisa é a Usina Alta Mogiana, que atua no comércio há mais de vinte e cinco anos na venda de açúcar e álcool, buscando a satisfação de seus clientes internos e externos, por acreditar ser esta a razão da existência do seu empreendimento, e também disponibiliza dados da organização a serem estudados, facilitando o acesso às informações.

\section{REVISÃO DA LITERATURA}

Roth (1998) afirma que no cotidiano das empresas a gestão da qualidade é peça fundamental para manter a competitividade e assegurar a sobrevivência. Organizações em todo o mundo praticam a gestão da qualidade através da adoção dos preceitos padronizados das normas ISO 9000. Dessa forma, a identificação, avaliação e análise das condições de implantação do modelo oferece subsídios para melhor compreensão dos impactos no resultado global da empresa, nos processos internos e nos procedimentos de trabalho.

Para isso, os resultados apresentados pelas empresas estudadas foram analisados de forma qualitativa e quantitativa com o fim de identificar as relações com a implantação do modelo ISO 9000. Além da análise dos registros, entrevistas foram aplicadas nos três níveis hierárquicos para que o estudo das opiniões refletisse a visão gerencial, de supervisão e de operação das empresas estudadas.

Andrade (2002) define que a era da globalização trouxe para as indústrias uma grande competição, nesse contexto é apregoado que só sobrevivem no mercado aquelas com diferencial a mais que as concorrentes. Uma das grandes diferenças é a qualidade total que tem como uma de suas ferramentas a certificação ISO série 9000.

O objetivo do sistema de certificação ISO série 9000 é assegurar que as indústrias obedeçam regulamentos e divulguem seus objetivos. Com isso a indústria pode obter benefícios como a implantação de um sistema de qualidade reconhecido mundialmente, possibilitando melhorias internas e um maior poder competitivo.

As indústrias buscam essa certificação esperando obter benefícios e vantagens apregoados pela literatura, auditores, consultores, dentre outros. 
Jobim (2002) questiona aspectos relacionados ao processo de implantação e manutenção de sistemas de gestão da qualidade em escritórios de projetos no Estado do Rio Grande do Sul. Há aproximadamente uma década, várias empresas de construção do Estado se engajaram no programa Qualidade Total, posteriormente no processo de certificação pela série de normas. NBR ISO 9000 e, mais recentemente, no processo de qualificação pelo Programa Brasileiro de Qualidade e Produtividade do Habitat. Além disto, pesquisadores, consultores e estudiosos têm se dedicado a propor modelos e acompanhar a implantação destes programas nas empresas.

Entretanto, parece que as metodologias adotadas ainda não conseguiram envolver devidamente os escritórios de projetos, pois o que se verifica no Rio Grande do Sul é uma pouca motivação para a implantação e manutenção de um sistema de gestão da qualidade nestes escritórios, dentro dos modelos propostos.

Godoy (2003) demonstra a ISO no mundo, no Brasil e no Rio Grande do Sul (RS), no estudo de caso, os dados foram levantados em duas empresas certificadas, mostrando-se as dificuldades e resistências que ocorreram durante e após a certificação.

Foram analisados também os principais impactos nos processos da construção civil, em relação às mudanças decorrentes da implantação de sistemas da qualidade ISO 9000 (1994/2000), em empresas na cidade de Santa Maria, (RS). As indústrias buscam essa certificação, esperando obter benefícios e vantagens como diferencial entre as concorrentes que não possuem certificação.

O autor procurou constatar, ainda, os pontos positivos e negativos para os dois níveis (direção e operacional) durante e após a implementação.

A conclusão que o autor chegou foi que a política organizacional das empresas em estudo, busca motivar os funcionários através de treinamento e reconhecimento permanente, facilitando a introdução de novas rotinas e novos procedimentos padronizados de trabalho.

Medeiros (2003) apresenta um modelo cuja proposta é a gestão integrada de qualidade, meio ambiente, segurança e saúde ocupacional, como uma ferramenta para o desenvolvimento sustentável. As questões de tecnologia, de competitividade, de desempenho, de custos, ambientais ou sociais têm afetado significativamente a maneira de agir das empresas e das pessoas em geral. A difusão e a disponibilidade da informação são crescente em um mundo globalizado, o que leva ao consumidor, uma gama de oportunidades no momento de adquirir bens e serviços.

Os consumidores mais exigentes passam a escolher não só os produtos com melhor relação preço e desempenho, mas consideram também a performance das empresas quanto à 
degradação ambiental e as questões sociais, difundidas através da divulgação dos conceitos de desenvolvimento sustentável, principalmente depois da Conferência da ONU de 1992, no Rio de Janeiro. Assim, o modelo apresentado no trabalho considera tanto as questões de crescimento e de desenvolvimento econômico das organizações, quanto as ambientais e sociais, advindas dos novos paradigmas do mundo moderno. Como resultado da aplicação do modelo, obteve-se a visualização da situação de uma empresa em estudo, frente aos indicadores de desempenho definidos.

Os resultados foram considerados satisfatórios e foram validados com base em sua consistência e importância para o melhoramento contínuo da empresa estudada. Dessa forma, considera-se que um sistema de gestão integrada, voltada para o desenvolvimento sustentável, pode ser uma importante ferramenta para o aumento da competitividade da empresa, no ambiente organizacional atual, que é de constante evolução.

Lima (2006) buscou explorar sobre implantação da NBR 14001 gera impactos nas organizações, pois demonstra a necessidade da realização de adequação na organização como um todo. Considerando a importância do assunto, foi conduzida uma pesquisa de caráter qualitativo em uma organização brasileira do setor elétrico, com o objetivo de apresentar as ações efetuadas na organização na busca de minimizar os riscos ambientais.

A empresa escolhida foi a CPFL, constituída por capital $100 \%$ nacional, com atuação em 234 municípios do interior de São Paulo. Esta organização atua na área de geração de energia elétrica, criada em 2002 é uma holding que controla, dentre outras, as empresas CPFL Geração de Energia ( empresa voltada para a geração de energia elétrica ), a CPFL Brasil ( que atua na comercialização de energia elétrica no mercado livre brasileiro )e a Companhia Paulista de Força e Luz ( CPFL Paulista empresa fundada em 16 de novembro de 1912 e presente no mercado há mais de noventa anos ). Após análise dos dados obtidos, conclui-se que é fundamental para a melhoria da empresa o desenvolvimento de uma política ambiental consistente, uma vez que ela se caracteriza como o principal alicerce do Sistema de Gestão ambiental. O presente artigo demonstra ainda a importância da conscientização e comprometimento de todos os níveis da organização na busca pela melhoria e preservação do meio ambiente.

\section{DESENVOLVIMENTO}

A organização escolhida foi a Usina Alta Mogiana fundada em 1983, para atender aos interesses nacionais lançados pelo Governo Federal em 1975 com o PROÁLCOOL - Programa 
Nacional do Álcool, que tinha por objetivo reduzir a dependência do Brasil do petróleo importado, face a dificuldade causada pela excessiva alta de preços mundiais.

A Usina Alta Mogiana orgulha-se em ser reconhecida publicamente pela sua produção altamente qualificada comprovada pelas certificações ISO 9002, OHSAS 18001 e ISO 22000. Mostra -se uma organização séria, com compromisso social e ambiental bem definidos, com o intuito de respeitar e colaborar para o crescimento de toda a comunidade que a acolheu.

Certificações de Qualidade :

ISO 9001 - É um sistema de gerenciamento de qualidade, seu modelo oferece garantia de padronização da produção, devidamente documentada e mantida com um acompanhamento constante através de auditorias. A certificação ISO 9002 possibilita á organização maior credibilidade junto aos clientes a confiabilidade da qualidade dos produtos e traz aos colaboradores qualidade nos serviços, com treinamentos, responsabilidade e envolvimento de toda a equipe.

ISO 22000 - A norma holandesa HACCP ( em português, APPCC - Análise de Perigos e Pontos de Controle ) estabelece pontos que controle que evitam a contaminação dos produtos alimentícios por meios físicos, químicos ou biológicos. Com sua implantação efetuada com sucesso, a empresa conquistou a certificação ISO 22000, garantia de que o açúcar como alimento ou como matéria - prima é produzido com a mais alta qualidade, sem risco de contaminação e com rastreabilidade produtiva, demonstração de confiabilidade.

OHSAS 18001 - A conquista da certificação OHSAS - 18001 é o reflexo do grande valor que a Usina Alta Mogiana dá a questões de segurança e saúde ocupacional dos seus colaboradores, através de operações sistematizadas e documentadas, treinamentos contínuo de segurança oferecido aos seus colaboradores e metas bem definidas de redução de acidentes.

Sem uso de qualquer incentivo oficial e com firme propósito de erguer uma organização vital para o desenvolvimento de São Joaquim da Barra, estado de São Paulo, tiveram sua primeira safra em 1985, com a moagem de cana total de 228 mil toneladas de cana e a produção de 17,8 milhões de litros de álcool hidratado.

Hoje a moagem de cana total chega a 1.188.533,1 toneladas somente nos primeiros seis meses do ano de 2008, que corresponde á uma produção de 1.518.841,0 sacas de açúcar, 101.010,0 sacas de açúcar peneirado, 34.404,0 m3 álcool total, 21.996,9 m3 álcool hidratado, 13.387,0 álcool anidro e 26.847,2 Mw de energia exportada.

A Usina Alta Mogiana é uma organização de resultados, voltada para o mercado e pessoas com a vocação de vanguarda técnica e de relacionamento ético, movida por uma 
estrutura simples e ágil, tem compromisso com 3.604 colaboradores. Definida como uma organização de resultados, voltada para o mercado e pessoas com vocação de vanguarda técnica e de relacionamento ético movida por:

- uma estrutura simples e ágil.

- compromissos com os colaboradores e com sua segurança no trabalho.

- compromissos com os clientes e parceiros.

- compromissos de crescimento e perpetuação da organização.

- responsabilidade social e ambiental.

O Sistema de Gestão Empresarial Alta Mogiana busca a satisfação de seus clientes internos e externos, priorizando valores como honestidade, cooperação e o compromisso de promover melhoria contínua, atendendo a legislação vigente e respeitando a segurança a saúde ocupacional e o meio ambiente, como bases para a busca de sua perpetuação.

Visão de produzir e comercializar alimentos e energia com foco no mercado satisfazendo os clientes e obtendo rentabilidade adequada, através do trabalho eficaz de todos.

Com a Missão de produzir e comercializar alimentos e energia com o foco no mercado, satisfazendo os clientes e obtendo rentabilidade adequada, através do trabalho eficaz de todos, de acordo com seus valores que são eles:

\section{a) Cliente :}

Criar, manter, satisfazer e encantar clientes internos e externos, pois eles são a razão de ser da Alta Mogiana.

\section{b) Honestidade :}

As atitudes praticadas pela Alta Mogiana e por seus colaboradores devem ser dignas, transparentes e coerentes fora e dentro da organização.

\section{c) Segurança, Limpeza e Organização :}

A limpeza, a segurança e a organização estão presentes em todas as atividades desenvolvidas visando um bom desempenho profissional e qualidade de vida no trabalho.

\section{d) Cooperação :}

O comprometimento com a integração e cooperação entre os colaboradores favorece o trabalho em equipe, transformando a Alta Mogiana em uma unidade forte, coesa e competitiva. 


\section{e) Respeito à pessoa do colaborador :}

A Alta Mogiana considera o colaborador como ser humano digno, com direito a ser ouvido e assistido, onde a individualidade de cada um é respeitada e, ao mesmo tempo, a organização espera a mesma relação entre os próprios colaboradores.

\section{f) Respeito ao Meio Ambiente :}

A preservação do meio ambiente é uma preocupação constante em todas as atividades desenvolvidas pela Alta Mogiana e por seus colaboradores.

\section{g) Valorização do Trabalho :}

A Alta Mogiana valoriza a criatividade e a iniciativa de cada um, incentivando o trabalho em equipe e proporcionando aos colaboradores oportunidades de autodesenvolvimento.

\section{h) Perpetuação :}

A Alta Mogiana investe em tecnologia e, com a participação dos colaboradores,busca o crescimento e competitividade visando à perpetuação da organização.

\subsection{MUDANÇAS PARA IMPLANTAÇÃO DA NORMA 14001}

\section{Comitê Ambiental}

A Usina Alta Mogiana aceitou um novo desafio implantar um Sistema de Gestão Ambiental, visando a certificação ISO 14001, para alavanca esse novo projeto foi criado um comitê com 11 colaboradores representantes das três divisões da organização como administrativo, industrial e agrícola.

O comitê Ambiental será responsável por promover a conscientização ambiental entre os colaboradores, identificar, avaliar e tratar os meios de sustentabilidade produtiva e manutenção de recursos naturais e coordenar as ações que possibilitarão a conquista desse certificado.

A fase de implantação consiste em conscientizar todos os colaboradores da organização acerca de suas responsabilidades pessoais com o meio ambiente e ações que podem ser desenvolvidas por cada um, para amenizar o impacto ambiental gerado em qualquer atividade humana ou industrial. 
Com isso surge os projetos de implantação da Usina Alta Mogiana que são eles :

\section{Projeto de Adequação Ambiental :}

Visando aliar produção agrícola à conservação dos recursos naturais da região, a Usina Alta Mogiana implantou um programa de adequação ambiental em suas áreas agrícolas . O projeto conta com a assessoria da ESALQ - USP e teve início em Outubro de 2002.

Possui um viveiro com capacidade para produzir 10.000 unidades de mudas de árvores e plantas em geral, com objetivo de conservar e reflorestar áreas de mananciais.

\section{Projeto Ambiental}

São ações que demonstram o interesse da organização em conservar os recursos naturais da região e da população como um todo, reforçando que com a tecnologia e vontade é possível conciliar produção agrícola e industrial e conservação dos recursos naturais e meio ambiente sem degradação alguma, com o processo de reciclagem.

O termo reciclar significa transformar objetos materiais usados ( ou lixo material ) em novos produtos para o consumo, esta necessidade foi despertada pelas pessoas comuns e governantes, a partir do momento em que observou -se os benefícios apresenta para o nosso planeta.

No processo de reciclagem, além de preservar o meio ambiente também gera renda, os materiais mais reciclados são vidros, o alumínio, o papel e o plástico. Esta reciclagem ajuda a diminuir significativamente a poluição da água, do ar e do solo. Muitas organizações estão reciclando materiais como uma maneira de diminuir os custos de produção de seus produtos..

O alumínio pode ser reciclado com um índice de reaproveitamento $100 \%$, derretido ele volta para as linhas de produção das indústrias de embalagens, caldeiras e etc, reduzindo os custos para a organização.Com isso surgiu o projeto de reciclagem do lixo, entre eles vidro, papel, alumínio, plástico, e lixo orgânico, com instalações de lixeiras personalizadas em diversos setores da organização.

\begin{tabular}{|c|c|}
\hline Lixeira Azul & Resíduos de papéis \\
\hline Lixeira Vermelha & Resíduos de plástico \\
\hline Lixeira Verde & Resíduos de vidros \\
\hline Lixeira Amarela & Resíduos de metais \\
\hline Lixeira Marrom & Resíduos de orgânicos \\
\hline Lixeira Laranja & Resíduos de pilhas \\
\hline
\end{tabular}




\section{Projeto de Geração com o Bagaço de Cana Alta Mogiana}

A geração de energia proveniente do bagaço de cana é apresentado como alternativa de tratamento de geração de energia, traz grandes benefícios com a utilização de fonte de alternativa de energia , com a valorização do resíduo .

É uma opção interessante do ponto de vista econômico para a utilização do bagaço de cana que gera energia elétrica , com a venda da sobra do bagaço obtido da queima conjunta das caldeiras já existentes. A utilização do bagaço apresenta viabilidade econômica tornandose uma opção interessante gerando lucros para a organização.

O Projeto Geração com o Bagaço de Cana Alta Mogiana é um projeto implantado, que visa a produção da organização de sua própria energia térmica e elétrica a partir do bagaço resultante da moagem da cana. A racionalidade dessa produção permite um excedente de energia gerada.

No início do projeto, em 2002 gerou cerca de 28.948 MWH de energia renovável para á Companhia Paulista de Força e Luz, com a qual possui contrato de venda de energia, já neste ano somente nos primeiros seis meses gerou cerca de 26.847,2 MWH.

\section{Projeto de Carbono}

Instrumento que possibilita implementar as resoluções tomadas na Convenção das Nações Unidas sobre mudanças climáticas, cujas metas objetivam reduzir e controlar as emissões de CO2 em até 2008-2012. As parte do Protocolo de Kioto poderão reduzir as suas emissões em nível doméstico e/ou terão a possibilidade de negociar os chamados “ sorvedouros “, tais como florestas e terras agrícolas de outro países. A organização tem autorização internacional para comercializar a outros países os créditos de carbono gerados por suas terras agrícolas. 
Projeto de Rentabilidade para a Organização e para o Meio Ambiente

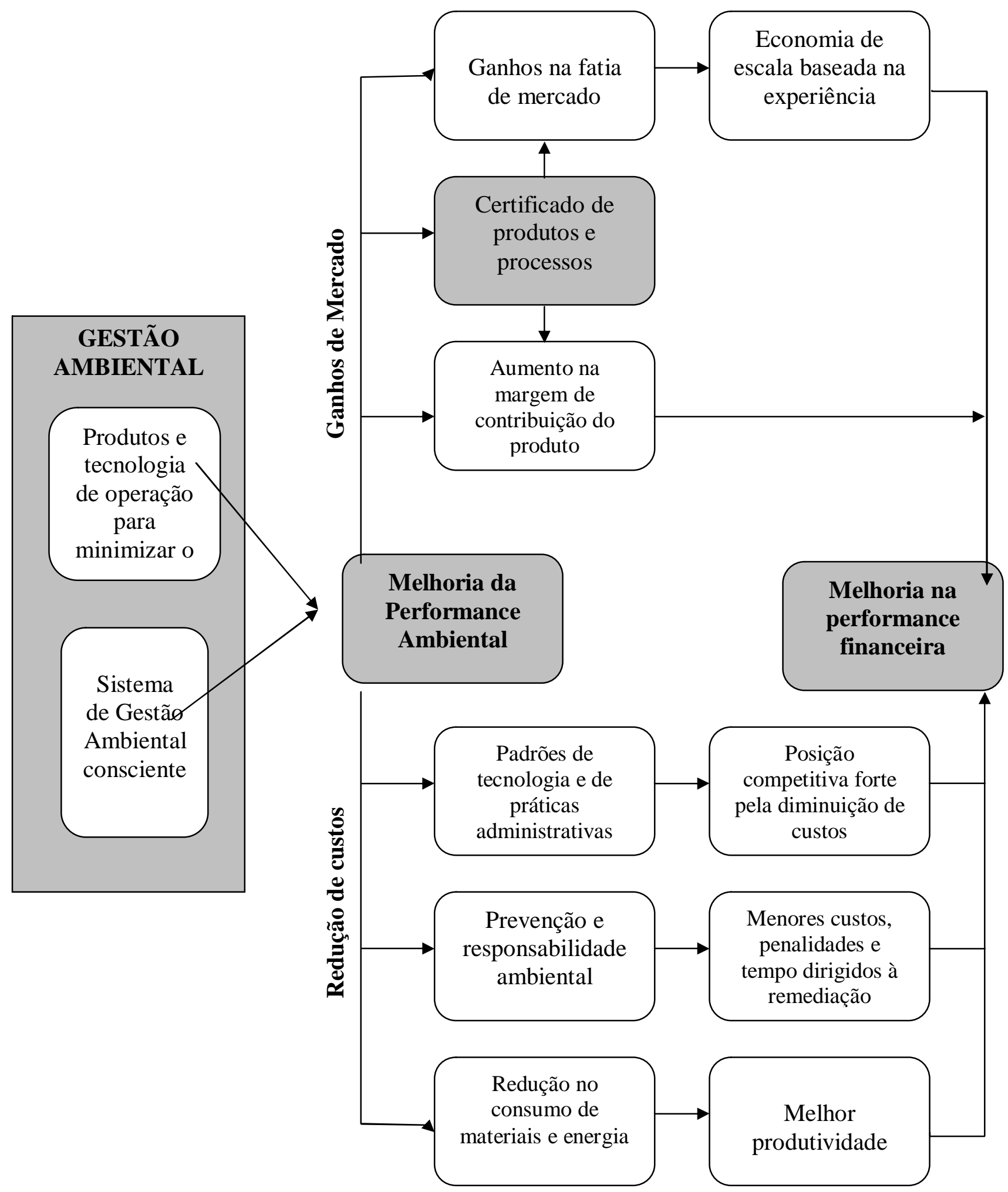




\section{Projeto de Reciclagem e Venda de Sucata.}

Projeto que visa utilizar os recursos da natureza, podendo ter muito em breve um ambiente mais limpo desenvolvido de forma sustentável, e de grande rentabilidade para a organização que gera uma receita, conforme mostra a tabela 1:

TABELA1: Venda de sucatas

\begin{tabular}{|c|c|c|c|c|}
\hline Produtos & 2005 & 2006 & 2007 & Total \\
\hline $\begin{array}{r}\text { Aço } \\
\text { Carbono }\end{array}$ & $255.633 \mathrm{~kg}$ & $140.029 \mathrm{~kg}$ & $151.714 \mathrm{~kg}$ & $547.376 \mathrm{~kg}$ \\
\hline Diversos & $148.153 \mathrm{~kg}$ & $75.516 \mathrm{~kg}$ & 8.139kg & $231.808 \mathrm{~kg}$ \\
\hline Cobre & $108.504 \mathrm{~kg}$ & $35.020 \mathrm{~kg}$ & $23.620 \mathrm{~kg}$ & $167.144 \mathrm{~kg}$ \\
\hline Sacaria & $19.087 \mathrm{~kg}$ & $65.435 \mathrm{~kg}$ & $5.328 \mathrm{~kg}$ & $89.850 \mathrm{~kg}$ \\
\hline Aço Inóx & $22.612 \mathrm{~kg}$ & $16.912 \mathrm{~kg}$ & $47.432 \mathrm{~kg}$ & $86.956 \mathrm{~kg}$ \\
\hline Pneus & $37.765 \mathrm{~kg}$ & 29.155kg & $12.630 \mathrm{~kg}$ & $79.550 \mathrm{~kg}$ \\
\hline $\begin{array}{r}\text { Canos } \\
\text { (evaporação) }\end{array}$ & 19.112.kg & $9.226 \mathrm{~kg}$ & $38.062 \mathrm{~kg}$ & $66.400 \mathrm{~kg}$ \\
\hline $\begin{array}{c}\text { Óleos } \\
\text { Queimados }\end{array}$ & $24.514 l t$ & 27.226lt & 12.213lt & 63.952lt \\
\hline Baterias & 19.077kg & $16.765 \mathrm{~kg}$ & $7.356 \mathrm{~kg}$ & $43.198 \mathrm{~kg}$ \\
\hline Bronze & $3.600 \mathrm{~kg}$ & $22.928 \mathrm{~kg}$ & 0kg & $26.528 \mathrm{~kg}$ \\
\hline Papelões & $2.705 \mathrm{~kg}$ & $3.005 \mathrm{~kg}$ & $1.651 \mathrm{~kg}$ & $7.361 \mathrm{~kg}$ \\
\hline Total & $660.761 \mathrm{~kg}$ & $441.216 \mathrm{~kg}$ & $308.145 \mathrm{~kg}$ & $1.410 .123 \mathrm{~kg}$ \\
\hline
\end{tabular}

\section{CONSIDERAÇÕES FINAIS}

O desenvolvimento e implantação de projetos de Gestão Ambiental exigem uma visão sistêmica organização/meio ambiente, que pode desencadear inovação e mudanças que gerem produtos com características ecológicas e processos mais eficientes, os quais podem ser promovidos através de estratégias de produção. Para as organizações talvez o maior beneficio seja a formação de uma imagem que as tornem mais atraentes diante do mercado globalizado, dando-lhe maior competitividade.

Pelo lado dos custos, a organização que investe pesadamente em Sistema de Proteção e Gestão Ambiental pode evitar futuros desastres, crises e responsabilidade ambientais, e minimizar custos de materiais desperdiçados. As organizações que caminham á frente da regulamentação minimizam o impacto ambiental de seus produtos, processos e atividades desenvolvidas e estão mais bem posicionadas diante dos padrões futuros. 
Entretanto o artigo teve a finalidade de identificar e avaliar os impactos causados pela implantação da ISO 14001 em uma organização brasileira do setor sucroalcooleiro , para isso, realizou-se uma pesquisa na Usina Alta Mogiana, reconhecida por sua excelência em qualidade.

Buscou-se verificar as mudanças e implantações vivenciadas na organização com a implantação dos projetos, que contribuiu no desenvolvimento de identificar e avaliar os impactos ambientais causados por sua produção e atividades.

Analisando o estudo, nota-se que os projetos implantados na organização obtiveram resultados excelentes que irão contribuir positivamente na busca de mais uma certificação.

Há que se considerar, também que grande parte das organizações certificadas pela ISO 14001 já possui o certificado ISO 9000. Dessa forma, se ambos os sistemas estiverem integrados, é possível que os benefícios da ISO 14001, se computados possam ser mais líquidos, devido à redução dos custos de implantação, certificação e manutenção do Sistema de Gestão Ambiental.

\section{REFERÊNCIAS}

ANDRADE, A C. Análise de benefícios relativos a clientes e produtos após à certificação ISO 9000, nas indústrias de Curitiba. jul.2002. Trabalho de Conclusão de Curso (Graduação em Administração de Empresa).

GODOY, L. P. Análise do cenário das certificações da ISO 9000 no Brasil. jul.003. Trabalho de Conclusão de Curso (Graduação em Administração de Empresas). Universidade Federal de Santa Maria.

IBAMA - Instituto Brasileiro do Meio Ambiente e dos Recursos Naturais Renováveis. Disponível em http: //www.ibama.gov.br/ecossistema/. Acesso em 05 maio 2008 às 11:40h.

JOBIM, M. S. S. Implantação e manutenção de sistema de gestão de qualidade em escritórios de projetos no estado do Rio Grande do Sul. jun. 2002. Trabalho de Conclusão de Curso ( Graduação em Engenharia). Universidade Federal de Santa Maria.

LIMA, R. de. O impacto causado pela implantação da NBR ISSO 14001. jul. 2006. Trabalho de Conclusão de Curso (Graduação em Administração de Empresa). Faculdade Integrada Metropolitana de Campinas.

MEDEIROS, E. B. Um modelo de gestão integrada de qualidade, meio ambiente segurança e saúde ocupacional para o desenvolvimento sustentável. maio 2003.151f. Dissertação (Mestrado em Engenharia de Produção). Universidade Federal de Santa Catarina, Florianópolis.

ROTH, J. L. Gestão da qualidade é peça fundamental para manter competitividade. jun. 1998. Trabalho de Conclusão de Curso (Graduação em Engenharia de Produção). Universidade Federal de Santa Maria. 